\title{
Screening, evaluation and selection of phosphate-solubilising fungi as potential biofertiliser
}

\author{
A. Morales ${ }^{1}$, M. Alvear ${ }^{1}$, E. Valenzuela ${ }^{2}$, C.E. Castillo ${ }^{3}$, F. Borie ${ }^{1}$ \\ ${ }^{1}$ Universidad de La Frontera, Facultad de Ingeniería, Ciencias y Administración, Departamento Ciencias \\ Químicas y Recursos Naturales. ${ }^{~}$ Scientific and Technological Bioresource Nucleus. Avenida Francisco \\ Salazar 01145, Temuco, Chile. ${ }^{2}$ Universidad Austral de Chile, Facultad de Ciencias, Instituto de Microbiolo- \\ gía, Casilla 167, Valdivia, Chile. ${ }^{3}$ Universidad Catolica de Temuco, Facultad de Recursos Naturales, Escuela \\ de Agronomia, Avenida Rudecindo Ortega 02950, Casilla 15-D, Temuco, Chile. *Corresponding author: \\ almoral@ufro.cl
}

\begin{abstract}
Phosphate-solubilising saprophytic fungi have a potential application in plant nutrition; therefore, the aim of this study was 1) to perform a screening and isolation of native phosphofungi from volcanic soils of southern Chile, 2) to select a liquid medium for the evaluation of these phosphofungi and 3) to test a selected phosphofungus as a biofertiliser in a volcanic soil.

The phosphofungi were screened using Martin medium (rose bengal-streptomycin agar) with calcium phosphate $\left(\mathrm{Ca}_{3}\left(\mathrm{PO}_{4}\right)_{2}\right)$ or calcium phytate as the phosphorus source. Six promising strains (Penicillium sp., Penicillium albidum, Penicillium thomii, Penicillium restrictum, Penicillium frequentans and Gliocladium roseum) were evaluated in the liquid media of Agnihotri, Asea-Wakelin, Pikovskaya and Nahas. The soluble phosphorus, acid phosphatase activity, $\mathrm{pH}$ and fungal biomass were determined.

In most soils, the greatest proportion of phosphofungi solubilised organic P. The Asea-Wakelin medium appears to be the medium of choice for the quantitative evaluation of phosphofungi isolated from the volcanic soils tested. Penicillium albidum was selected as a potential biofertiliser due to its capacity to solubilise both inorganic and organic $\mathrm{P}$ via its specific solubilising activity (64 mg P/g fungus), phosphatase secretion and enhancement of the growth and mineral nutrition of lettuce plants growing in a volcanic soil.
\end{abstract}

Keywords: phosphate solubilising-mineralising fungi; Penicillium albidum; phosphatase; lettuce 


\section{Introduction}

Phosphorus $(\mathrm{P})$ is incorporated in a series of fundamental cellular molecules, such as phospholipids, nucleic acids and nucleotides, making it an essential macronutrient for any organism. This nutrient is acquired by plants from the soil solution mainly in the form of $\mathrm{H}_{2} \mathrm{PO}_{4}^{-}$and $\mathrm{HPO}_{4}^{2-}$. Some soils, however, particularly volcanic soils, possess a high capacity to fix phosphate, thus limiting the bioavailability of $\mathrm{P}$. This necessitates the application of significant doses of phosphate fertiliser to these soils each year, an expensive process that ultimately results in the accumulation of inorganic and organic $\mathrm{P}$ in significant quantities, the latter mainly in the form of monoester phosphate and diester phosphate (Borie and Rubio, 2003; Redel et al., 2008). As a result, these soils are deficient in available $\mathrm{P}$ but contain high levels of total $\mathrm{P}$, which increases annually as a result of the excessive fertilisation (Borie and Rubio, 2003).

It is crucial to take advantage of the accumulated $\mathrm{P}$ in the soil, improving the growth of vegetables while reducing fertiliser consumption. In this respect, the use of microorganisms in the rhizosphere that are capable of mobilising $\mathrm{P}$ into available forms as biofertilisers is feasible, particularly in sustainable agriculture. Hence, there is enormous interest in isolating phosphate-solubilising microorganisms, including phosphate-solubilising and -mineralising saprophytic fungi (phosphofungi), due to their large biomass, metabolic activity and ability to maintain their solubilising capacity for years; such phosphofungi have been isolated from various soils (Borie et al., 1983; Pandey et al., 2008). The mechanisms of inorganic phosphate solubilisation are associated mainly with the acidification of the medium and organic acid production, whereas these fungi must produce phosphatase enzymes to mineralise organic P. In addition, some of these fungi present other characteristics, such as a wide range of tolerance for temperature, $\mathrm{pH}$ and salt concentration (Pandey et al., 2008) and phytohormone or siderophore production (Vassileva et al., 2010).

Phosphofungi belong predominantly to the $A s$ pergillus and Penicillium genera, and several strains have been identified that benefit the nutrient concentrations and yield of vegetables under both greenhouse and field conditions (Whitelaw, 2000). However, the beneficial effect on plants may be influenced by several factors, including the type of soil and its level of $\mathrm{P}$, inadequate laboratory methods for selecting the fungi or a poor understanding of the interactions of the inoculated microorganisms with the soil. One strategy to overcome these limitations is the use of native phosphofungi adapted to the edaphoclimatic conditions of each region, an approach that would require the identification and isolation of native phosphofungi and their subsequent evaluation and would advance the knowledge of phosphofungus-soil-plant interrelationships.

Indeed, research in this area is becoming critical because the great majority of $\mathrm{P}$ fertilisers are obtained from phosphate rock, a non-renewable source of $\mathrm{P}$ that is expected to be exhausted in 30 to 50 years and because the exploited deposits are of increasingly lower quality, which results in increases in the cost of phosphate fertiliser production.

Thus, the use of phosphofungi in volcanic soils in Chile, alone or co-inoculated with mycorrhizal fungi, would be relevant for agriculture, particularly in the development of sustainable agriculture in which these types of microorganisms have great 
potential. Given the large amount of agricultural activity that these types of soils maintain, this would also have significant financial and environmental impacts.

Therefore, the aim of this study was 1) to perform a screening and isolation of native phosphofungi from volcanic soils from the south of Chile, 2) to select a liquid medium to quantify the P-solubilising capacity of the phosphofungi, and 3) to test a phosphofungus as a biofertiliser in a volcanic soil.

\section{Materials and methods}

\subsection{Screening and isolation of phosphofungi}

Phosphofungi from 21 volcanic soils from southern Chile (Araucanía region) were screened. These soils included those that sustained crops with different agronomic management to increase the probability of isolating phosphofungi with high P-solubilising capacity. The main soil characteristics are shown in Table 1.

Table 1. Basic characteristics of the soils used.

\begin{tabular}{cllccc}
\hline Site & $\begin{array}{l}\text { Soil order } \\
\text { (series) }\end{array}$ & $\begin{array}{l}\text { Management } \\
\text { system }\end{array}$ & $\mathbf{p H}\left(\mathbf{H}_{2} \mathbf{O}\right)$ & $\begin{array}{c}\text { Olsen-P } \\
(\mathbf{m g P} / \mathbf{k g})\end{array}$ & O.M. (\%) \\
\hline 1 & Andisol (Freire) & Organic farming, maize & 5.60 & 16.9 & 15.3 \\
2 & Andisol (Freire) & Natural pasture & 5.33 & 2.5 & 22.1 \\
3 & Andisol (Temuco) & Organic farming, & & & \\
4 & & garlic & 6.08 & 17.5 & 14.1 \\
& & pasture & & \\
5 & Andisol (Temuco) & Natural pasture & 5.62 & 8.4 & 16.4 \\
6 & Andisol (Temuco) & Vegetable & 5.50 & 7.9 & 15.9 \\
7 & Ultisol (Metrenco) & Organic farming, & & & \\
8 & & natural pasture & 5.70 & 11.2 & 10.1 \\
& & wheat & 5.67 & 15.6 & 6.2 \\
9 & Ultisol (Metrenco) & NT, lupine & 5.51 & 16.9 & 9.3 \\
10 & Ultisol (Vilcún) & NT, wheat & 5.43 & 23.8 & 11.6 \\
11 & & RT, wheat & 5.49 & 19.2 & 11.0 \\
12 & & CTS, wheat & 5.26 & 21.9 & 8.6 \\
13 & & CTB, wheat & 5.34 & 17.9 & 9.2 \\
\hline
\end{tabular}

(O.M., organic matter; NT, no-tillage; RT, reduced tillage; CTS, conventional tillage with stubble retained; CTB, conventional tillage with stubble burned)

The phosphofungi were isolated from the rhizosphere using serial dilution and were plated on rose bengalstreptomycin agar (Martin, 1950), with calcium phosphate or calcium phytate added as an insoluble source of inorganic or organic $\mathrm{P}$, respectively. On either medium, a halo around the colony indicates solubility.
The plates were incubated for 5 days at $28^{\circ} \mathrm{C}$, and the number of solubilising colonies, their total diameter (colony + halo), and the diameter of the colony were then determined. A solubilisation index was calculated using total / diameter of the colony ratio (Fankem et al., 2006). Those colonies with the greatest diam- 
eter and solubilisation index were selected to be reevaluated using Martin medium. The total number of colonies was also determined.

\subsection{Re-evaluation on Martin medium and identification of phosphofungi}

Selected colonies were replicated several times using Martin medium and re-evaluated for effects on calcium phosphate or calcium phytate. The medium for the organic P (the latter) had phenolphthalein phosphate added to detect phosphatase release; a red halo around the colony, as revealed with ammonia fumes, indicated phosphatase release (Barik et al., 2001).

These fungi were identified through their growth rate for 5 days on $2 \%$ malt agar at $23 \pm 2{ }^{\circ} \mathrm{C}$. To determine the reproductive, resistance and vegetative structures, fresh cultures were prepared from the colonies that had formed by the fifth day, and their characteristics were compared with taxonomic keys according to von Arx (1981) to identify the fungi at the genus level. To determine the species, each isolate was cultured on $2 \%$ CZpex agar and $2 \%$ potato dextrose agar and incubated at $23 \pm 2{ }^{\circ} \mathrm{C}$ for 5 days to determine the macroscopic characteristics of the colonies (colour, margin, texture, odour and height). The characteristics and measurements of the reproductive, resistance and vegetative structures were determined using microscopic preparations. All of the data obtained were compared with taxonomic keys (Ramírez 1982; Domsch et al., 1995).

\subsection{Quantification of the solubilising capacity in liquid medium}

Based on the solubility index, diameter of the colony, total diameter and capacity to release phosphatase in Martin medium, isolates were selected for evaluation in the 4 following liquid media using $\mathrm{Ca}_{3}\left(\mathrm{PO}_{4}\right)_{2}$ as the
P source: 1) Agnihotri (1970), 2) Asea et al. (1988), modified by Wakelin et al. (2004), 3) Pikovskaya (1948), and 4) Nahas et al. (1994). The compositions of these media are provided in Table 2. Mycelium circles of $3 \mathrm{~mm}$ in diameter obtained from colonies growing on Martin agar were inoculated in $50 \mathrm{~mL}$ of liquid medium and cultivated in the dark at $20^{\circ} \mathrm{C}$ with intermittent orbital agitation at $100 \mathrm{rpm}$ for 9 minutes every hour. At the end of 7 days, the liquid phase was separated by filtration, the $\mathrm{pH}$ and soluble $\mathrm{P}$ were determined using the method of Murphy and Riley (1962), and the acid phosphatase activity was determined according to Rubio et al. (1990). The fungal mass was determined in the solid phase as the difference between the mass at $60^{\circ} \mathrm{C}$ for 24 hours and the mass of the residue after being subjected to calcination in a muffle furnace at $500^{\circ} \mathrm{C}$ for 6 hours (Reyes et al., 1999). The controls included the same treatments but without the phosphofungi. All of the treatments were performed in quadruplicate.

\subsection{Inoculation of a selected fungus in lettuce- growing soil}

A fungus with a high capacity for solubilising phosphate and releasing phosphatase in liquid medium was selected to evaluate its effect on the development of lettuce (Lactuca sativa L.) in situ. This assay comprised a) a seedbed stage under greenhouse conditions and b) subsequent transplanting and development under shaded field conditions.

\section{Seedbed stage}

Lettuce seeds (L. sativa) were disinfected with water at $45^{\circ} \mathrm{C}$ for 24 hours and then allowed to germinate for 3 days. Each seedling was placed in the cell of a speedling tray containing $100 \mathrm{~mL}$ of a non-sterile mixture of soil (Andisol, $\mathrm{pH}=5.7$, available $\mathrm{P}=8$ 
$\mathrm{mg} \mathrm{kg}{ }^{-1}$ ), sand, vermiculite and compost (4.5:4:0.5:1). At the beginning of the seedbed stage, the soil of ten plants was inoculated with $1.9 \times 10^{6} \mathrm{CFU}$ of the phosphofungus, and another 10 seedlings were controls without fungi. The inoculum consisted of a mycelium suspension obtained by culture in Sabouraud broth at $20{ }^{\circ} \mathrm{C}$ for five days, followed by filtration, washing and resuspension in sterile water. The speedling trays remained in the greenhouse; at the end of 2 months, the aerial and root weights of the plants and the soil Olsen-P were recorded for five replications of the inoculated and non-inoculated soil. P-solubilising colonies and the acid phosphatase activity (Rubio et al., 1990) were also evaluated. The ten remaining plants (five control and five treated) were transplanted.

\section{Transplant stage}

At the end of the seedbed stage, the remaining plants were transplanted to $1 \mathrm{~L}$ pots containing the above- described soil, sand, vermiculite and compost mixture plus worm humus at a ratio of 60:40 and grown outdoors under shade. At five months after transplanting, the aerial weights of the plants (total, heart, stem, and leaves) were determined, and the nutrient concentrations ( $\mathrm{P}, \mathrm{K}, \mathrm{Ca}, \mathrm{Mg}, \mathrm{Mn}, \mathrm{Cu}, \mathrm{Zn}$, and $\mathrm{Fe}$ ) were measured using $1 \mathrm{~g}$ of dry matter that was calcined in a muffle furnace at $480{ }^{\circ} \mathrm{C}$ for 8 hours. The resulting ashes were treated with $2 \mathrm{M} \mathrm{HCl}$; the $\mathrm{P}$ was determined using spectrophotometry, and the remaining elements were analysed using atomic absorption (Sadzawka et al., 2004).

\subsection{Statistical analysis}

For the statistical analysis of the liquid medium results, a one-way ANOVA was used, and the averages were compared using the LSD test $(p<0.05)$. A student's ttest $(p<0.05)$ was used for the correlation coefficients and the testing of the lettuce soil inoculation.

Table 2. Composition of the liquid media used to quantify the calcium phosphate solubilisation by the selected phosphofungi.

\begin{tabular}{|c|c|c|c|c|}
\hline \multirow{2}{*}{ Media component } & \multicolumn{4}{|c|}{ Amount ( $\left.\mathrm{g} \mathrm{L}^{-1}\right)$} \\
\hline & Agnihotri & Asea-Wakelin & Pikovskaya & Nahas \\
\hline $\mathrm{NaCl}$ & & 0.1 & - & 0.1 \\
\hline $\mathrm{NH}_{4} \mathrm{Cl}$ & & 0.4 & - & 1.0 \\
\hline $\mathrm{KNO}_{3}$ & & 0.78 & - & - \\
\hline $\mathrm{MgSO}_{4}$ & 0.5 & 0.5 & - & - \\
\hline $\mathrm{CaCl}_{2} \cdot 2 \mathrm{H}_{2} \mathrm{O}$ & & 0.1 & - & 0.1 \\
\hline Sucrose ${ }^{2}$ & & 10 & - & - \\
\hline $\mathrm{NaNO}_{3}$ & 5 & - & - & - \\
\hline $\mathrm{KCl}^{3}$ & & - & 0.2 & 0.2 \\
\hline $\mathrm{MgSO}_{4} \cdot 7 \mathrm{H}_{2} \mathrm{O}$ & & - & 0.1 & 1.2 \\
\hline Glucose & 15 & - & 10 & 10 \\
\hline Yeast extract & & - & 0.5 & 0.5 \\
\hline $\mathrm{FeSO}_{4} \cdot 7 \mathrm{H}_{2} \mathrm{O}$ & & - & 0.002 & - \\
\hline $\mathrm{MnSO}_{4} \cdot \mathrm{H}_{2} \mathrm{O}$ & & - & 0.002 & - \\
\hline$\left(\mathrm{NH}_{4}\right)_{2} \mathrm{SO}_{4}$ & & - & 0.5 & - \\
\hline $\mathrm{Ca}_{3}\left(\mathrm{PO}_{4}\right)_{2}$ & 2 & 2 & 2 & 2 \\
\hline
\end{tabular}




\section{Results and discussion}

\subsection{Screening and isolation of phosphofungi}

In all of the soils sampled, phosphofungi were found on the order of $10^{4} \mathrm{CFU}$ per gram of soil, independent of the soil type (Table 3). In most soils, the organic phosphatesolubilising CFU represented between 10 and $35 \%$ of the total fungi, where the percentage of organic P solubilisers appeared to be higher than that of the inorganic P solubilisers (Table 3), results similar to those found in a previous screening (Borie et al., 1983). The influence of the soil management on the amount of fungi was most evident in the Ultisol Vilcún series, with results showing that NT (no tillage) and RT (reduced tillage), compared to CT (conventional tillage), contributed to an increase in the total number of fungi and the percentage of phosphofungi (Table 3). Stubble burning also contributed to the abundance of fungi in the soil when compared to the soil without burning (Table 3), possibly due to an increased mineralisation and availability of some nutrients, favouring microbial growth, particularly phosphofungi. In contrast, Wang et al. (2010) did not find any effect of stubble burning on the saprophytic fungi in the soil; therefore, such factors require further study.

Most of the colonies detected had a low solubility index $(\leq 1.15)$ (Figure 1). When this index increased, the number of solubilising colonies decreased, but the proportion of solubilising colonies of calcium phytate increased. In these soils, the phosphofungi solubilising organic $\mathrm{P}$ exceeded the percentage of the phosphofungi solubilising inorganic $\mathrm{P}$, suggesting an adaptation of the fungi to such edaphic conditions with high contents of organic P. This adaptation was also suggested by Borie et al. (1983), who found that phosphofungi had a greater ability than bacteria to solubilise organic phosphates in volcanic soils.

Table 3. Total and solubilising fungi isolated from different volcanic soils.

\begin{tabular}{|c|c|c|c|c|c|c|}
\hline \multirow{3}{*}{ Site } & \multirow{3}{*}{ Management system } & \multicolumn{4}{|c|}{ Fungi on Martin medium (CFU/g.d.s) } & \multirow{3}{*}{ Main fungi isolated } \\
\hline & & \multicolumn{2}{|c|}{+ inorganic $\mathbf{P}$} & \multicolumn{2}{|c|}{+ organic $\mathbf{P}$} & \\
\hline & & Total & solubilising & Total & solubilising & \\
\hline 1 & Organic farming, maize & $6 \times 10^{5}$ & $5 \times 10^{4}(8)$ & $6 \times 10^{5}$ & $6 \times 10^{4}(10)$ & $\begin{array}{l}\text { Penicillium restrictum } \\
\text { Penicillium frequentans } \\
\text { Penicillium jensenii } \\
\text { Eupenicillum javanicum } \\
\text { Myrothecium roridum }\end{array}$ \\
\hline 2 & Natural pasture & $2.2 \times 10^{5}$ & $5 \times 10^{4}(23)$ & $2.2 \times 10^{5}$ & $6 \times 10^{4}(27)$ & Penicillium sp. \\
\hline 3 & Organic farming, garlic & $8 \times 10^{4}$ & $1 \times 10^{4}(12)$ & $1 \times 10^{5}$ & $3 \times 10^{4}(30)$ & Gliocladium roseum \\
\hline 4 & Organic farming, pasture & $1.7 \times 10^{5}$ & $5 \times 10^{4}(29)$ & $2.2 \times 10^{5}$ & $7 \times 10^{4}(32)$ & \\
\hline 5 & Natural pasture & $1.8 \times 10^{5}$ & $3 \times 10^{4}(17)$ & $1.8 \times 10^{5}$ & $2 \times 10^{4}(11)$ & Myrothecium roridum \\
\hline 6 & Vegetable & $1.5 \times 10^{5}$ & $1 \times 10^{4}(7)$ & $1.6 \times 10^{5}$ & $2 \times 10^{4}(13)$ & \\
\hline 7 & Organic farming, pasture & $1.7 \times 10^{5}$ & $4 \times 10^{4}(24)$ & $1.8 \times 10^{5}$ & $4 \times 10^{4}(22)$ & \\
\hline 8 & Organic farming, pasture & $1.8 \times 10^{5}$ & $6 \times 10^{4}(33)$ & $1.7 \times 10^{5}$ & $6 \times 10^{4}(35)$ & Penicillium thomii \\
\hline 9 & NT, Lupine & $1.8 \times 10^{5}$ & $2 \times 10^{4}(11)$ & $1.9 \times 10^{5}$ & $4 \times 10^{4}(21)$ & \\
\hline 10 & NT, wheat & $2.4 \times 10^{5}$ & $7 \times 10^{4}(29)$ & $2.4 \times 10^{5}$ & $8 \times 10^{4}(33)$ & Penicillium albidum \\
\hline 11 & RT, wheat & $2.3 \times 10^{5}$ & $6 \times 10^{4}(26)$ & $2.3 \times 10^{5}$ & $7 \times 10^{4}(30)$ & \\
\hline 12 & CTS, wheat & $1.8 \times 10^{5}$ & $3 \times 10^{4}(17)$ & $1.9 \times 10^{5}$ & $5 \times 10^{4}(26)$ & \\
\hline 13 & CTB, wheat & $2.1 \times 10^{5}$ & $5 \times 10^{4}(24)$ & $2.4 \times 10^{5}$ & $8 \times 10^{4}(33)$ & \\
\hline
\end{tabular}

(Values in parentheses represent the percentage of solubilising fungi. NT, no-tillage; RT, reduced tillage; CTS, conventional tillage with stubble retained; CTB, conventional tillage with stubble burned; g.d.s., grams of dry soil). 


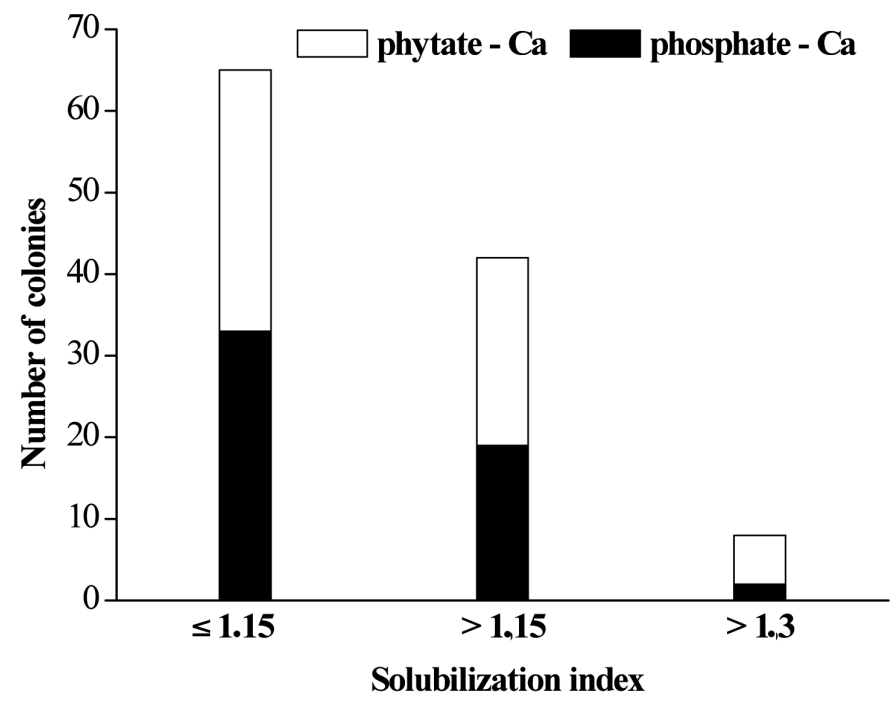

Figure 1. Number of phosphate- and calcium phytate-solubilising colonies in relation to the solubility index.

Based on the colony diameter and solubilisation index, the phosphofungi selected and purified from successive cultures on Martin agar were identified according to taxonomic keys as Penicillium sp., $P$. albidum, $P$. thomii, $P$. restrictum, $P$. frequentans, Gliocladium roseum, Myrothecium roridum, P. jensenii and Eupenicillum javanicum (Tables 3 and 4). Five of these species were isolated from an Andisol Freire series under organic agriculture and cropped with maize. However, only a single species was isolated from this same type of soil under natural pasture conditions in a nearby site (Table 3), suggesting that organic agriculture increases the diversity of these fungi, which is consistent with the reports on the fungal diversity (Mäder et al., 2002), total fungi and active fungi (Shannon et al., 2002) found in organic agriculture. Furthermore, the type of plant cultivated is also significant because, in this study, the soil used under organic agriculture with garlic as the main crop presented a low range of both total fungi and P solubilisers. It has been indicated previously that garlic possesses antimicrobial and anti-fungal substances (Irkin and Korukluoglu, 2009), which suggests that these substances are exuded into the soil through the root, decreasing the fungal population. One species (P. albidum) was isolated from a Ultisol Vilcún under NT, but none were found under RT or CT, probably due to a greater wealth and diversity of saprophytic fungi under NT soils compared with CT soils.

Of the phosphofungi selected at this stage, $P$. thomii and $P$. restrictum have been reported as phosphofungi, although it has also been indicated that the former produces plant growth inhibiters. In contrast, the remaining fungi have been reported in different studies, including those regarding volatile hydrocarbon production (Gliocladium roseum), a biological control agent against rotting of stone fruits (P. frequentans), the production of anti-fungal sub- 
stances (Eupenicillium javanicum), or even antibiotic production ( $P$. albidum). Therefore, such additional properties have acquired relevance with respect to the use of phosphofungi in the manufacture of multifunctional biofertilisers as well as in the treatment of agro-industrial wastes, composting or the control of phytopathogens (Vassileva et al., 2010), indicating the broad biotechnological potential of these microorganisms. However, the presence of some fungi with pathogenic characteristics or growth inhibitors, such as Myrothecium roridum, a fungus pathogenic to some plants, emphasises the use of caution in applications.

The P. albidum, P. thomii, P. restrictum, P. frequentans and Gliocladium roseum isolates demonstrated two important characteristics in the mobilisation of $\mathrm{P}$ in volcanic soils, the solubilisation of inorganic $\mathrm{P}$ and the mineralisation of organic $\mathrm{P}$ (Table 4), which is consistent with the approach of producing biofertilisers with more than one function.

Table 4. Evaluation of the phosphate solubilising ability of the selected fungi on Martin medium.

\begin{tabular}{lccccccc}
\hline \multirow{2}{*}{ Species } & \multicolumn{3}{c}{ Inorganic P } & \multicolumn{3}{c}{ Organic P } & \multirow{2}{*}{ P-ase } \\
\cline { 2 - 6 } & T.D. & C.D. & S.I. & T.D. & C.D. & S.I. & \\
\hline Penicillium albidum & 3.4 & 2.8 & 1.2 & 4.7 & 4.4 & 1.1 & ++ \\
Penicillium thomii & 3.4 & 2.8 & 1.2 & 4.0 & 3.8 & 1.1 & ++ \\
Penicillium restrictum & 5.0 & 4.0 & 1.3 & 4.0 & 3.0 & 1.3 & ++ \\
Penicillium frequentans & 2.1 & 1.9 & 1.1 & 2.2 & 1.7 & 1.3 & ++ \\
Gliocladium roseum & 3.0 & 2.6 & 1.2 & 5.4 & 5.0 & 1.1 & ++ \\
Myrothecium roridum & 2.5 & 1.9 & 1.3 & 3.5 & 2.0 & 1.8 & - \\
Penicillium jensenii & 1.6 & 1.4 & 1.1 & 2.0 & 1.8 & 1.1 & + \\
Eupenicillium javanicum & 1.7 & 1.4 & 1.2 & 2.4 & 2.0 & 1.2 & + \\
\hline
\end{tabular}

(T.D. total diameter; C.D. colony diameter; S.I. solubility index; + colour intensity)

\subsection{Behaviour of the selected fungi in liquid media}

Therefore, for their capacity to solubilise phosphate and calcium phytate and produce phosphatase (Pase) were quantitatively evaluated in liquid media the following isolates: Penicillium albidum, Penicillium thomii, Penicillium restrictum, Penicillium frequentans, Gliocladium roseum, and the Penicillium sp. The greatest total solubilising capacity of $P$. albidum and $P$. thomii was found in the Pikovskaya medium, whereas the Penicillium sp., P. restrictum and $P$. frequentans exhibited the highest level in the Asea-Wakelin medium and Gliocladium roseum exhibited the highest level in the Nahas medium (Figure
2A). Therefore, one half of the isolates solubilised the greatest amount of $\mathrm{P}$ in the Asea-Wakelin medium. We found no medium in which all of the fungi expressed their capacity to solubilise $\mathrm{P}$ with equal efficiency, similar to the results of Xie et al. (2009) for bacteria. Nevertheless, these results indicate that the majority of the native phosphofungi in southern Chile will manifest their ability to solubilise $\mathrm{P}$ best in AseaWakelin medium.

There was a general acidification of the liquid media (Figure 2B), and there have been reports of the independent and dependent mechanisms of $\mathrm{NH}_{4}^{+}$ acidification (Asea et al., 1988) that must be related to the solubilisation of P. In this study, P. albidum, 
P. frequentans and P. restrictum even acidified the Agnihotri medium, which only contains $\mathrm{N}$ in the form of $\mathrm{NO}_{3}$ - The significant negative correlation $(p<0.05)$ between the variation in the $\mathrm{pH}$ of the medium and the solubilised total $\mathrm{P}(\mathrm{r}=-0.91$ in Asea-Wakelin, $\mathrm{r}=$ -0.91 in Pikovskaya, $r=-0.90$ in Nahas and $r=-0.87$ in Agnihotri) is also remarkable, i.e., the greater the $\mathrm{P}$ solubilisation was, the more the $\mathrm{pH}$ decreased. Accordingly, the acidification of the medium explains to a large extent the in vitro solubilisation of calcium phosphate, possibly due to the release of organic acids by these fungi (Wakelin et al., 2004; Pandey et al., 2008).
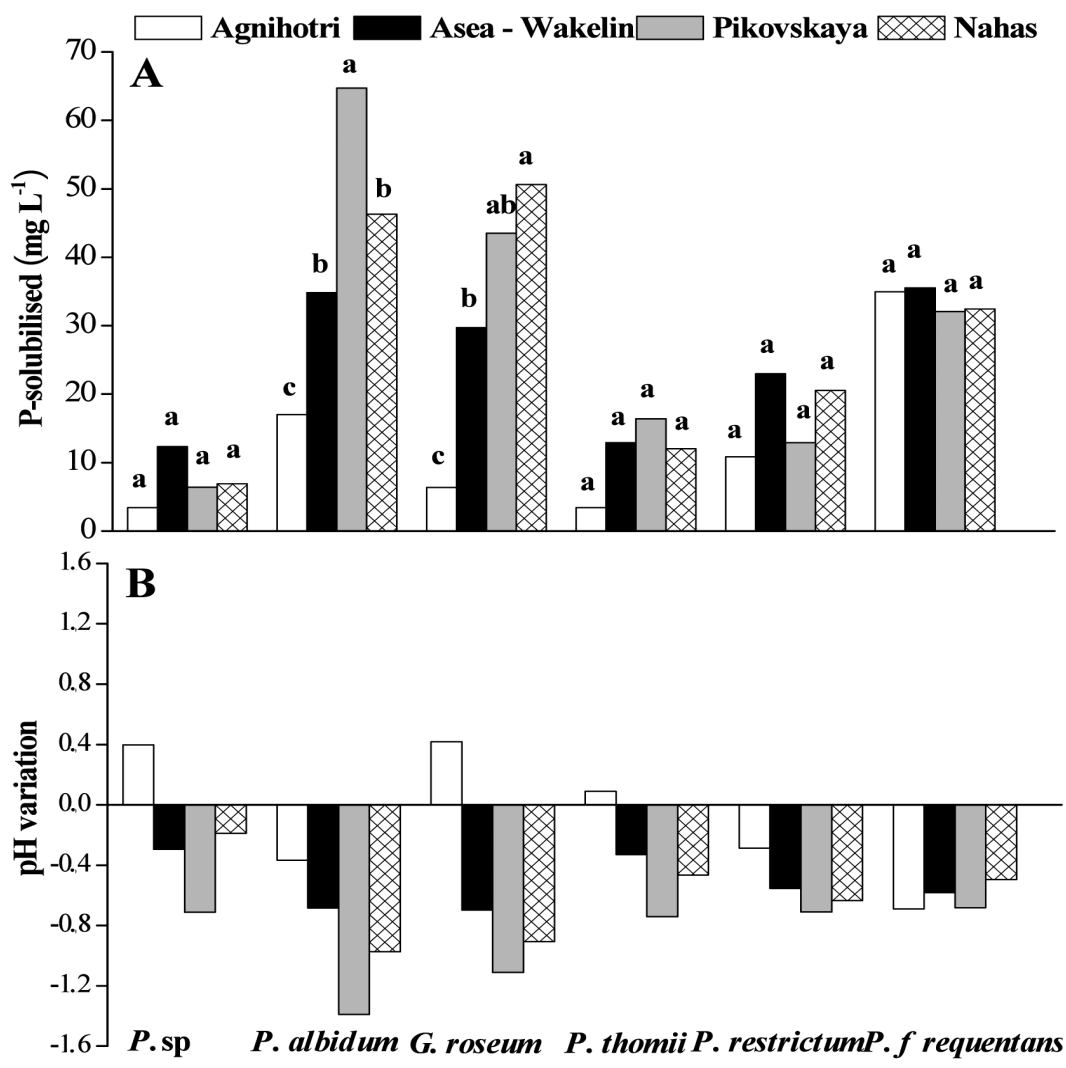

Figure 2. A) Total solubilised phosphorus and B) $\mathrm{pH}$ variation in the liquid media. Bars with different letters indicate significant differences between the culture media for the same fungus by $\operatorname{LSD}(p<0.05)$ 
When standardising the solubilised $\mathrm{P}$ with respect to the fungal mass (specific solubilising activity), it was observed that the phosphofungi exhibited a high specific solubilising activity in the Asea-Wakelin medium (Figure 3), with $P$. albidum (64 mg P/g fungus, $p<0.05)$ displaying a particularly high level. These results indicate that the metabolism of the fungi is aimed more toward the solubilisation of $\mathrm{P}$ in Asea-
Wakelin medium, which is more restricted in nutrients compared with the Pikovskaya and Nahas media that contain yeast extract. Accordingly, it is possible that the fungi with a high specific solubilising activity in the Asea-Wakelin medium have a greater potential as biofertilisers, given that adverse conditions, such as the low availability of nutrients, is common to many soils.

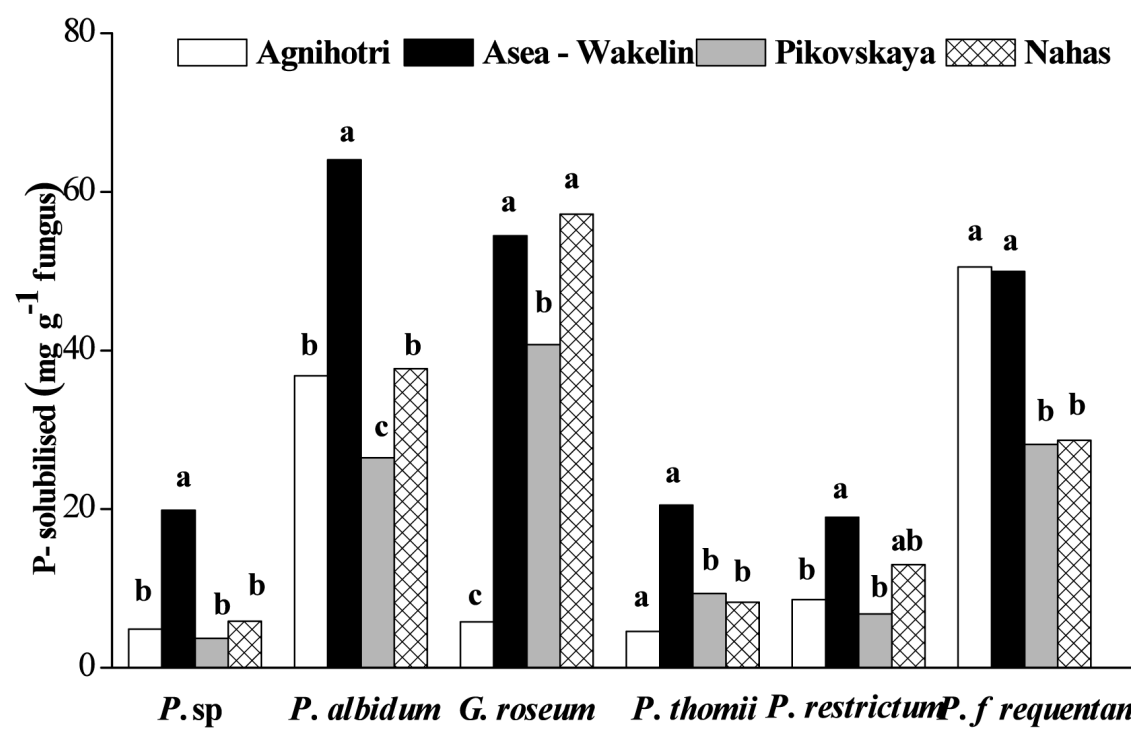

Figure 3. Specific solubilising activity in liquid media. Bars with different letters indicate significant differences between the culture media for the same fungus by $\operatorname{LSD}(p<0.05)$

The greatest acid phosphatase secretion per gram of fungus was observed in the Asea-Wakelin medium, reinforcing the idea that the metabolism of the phosphofungi is aimed more at the mobilisation of $\mathrm{P}$ in this medium. Again, P. albidum was prominent in this medium, together with the Penicillium sp. and P. thomii (Figure 4). 


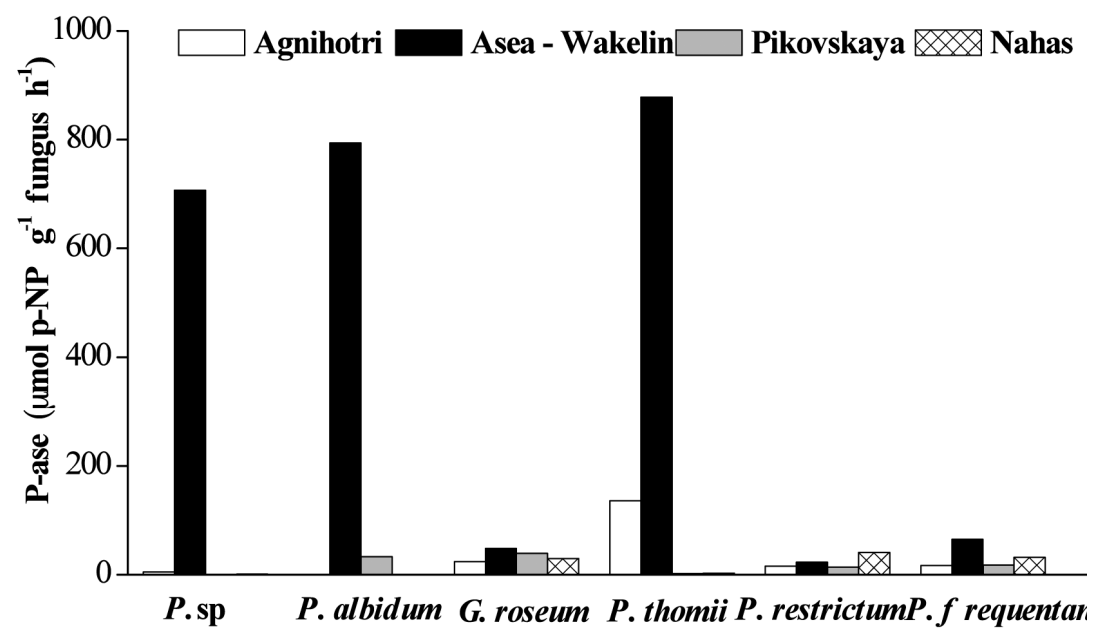

Figure 4. Extracellular acid phosphatase activity.

\subsection{Effect of inoculation}

Considering its capacity to solubilise both organic and inorganic $\mathrm{P}$ and its elevated P-ase activity, P. albidum appears to have the greatest potential to release P for the benefit of plants; therefore, it was selected to evaluate the in situ effect on lettuce growth. After two months of growth (the end of the seedbed stage), the results indicated that inoculation with $P$. albidum significantly increased both the aerial and the root weights (Table 5). These results are similar to those reported by Kohler et al. (2007) in lettuce inoculated with Aspergillus niger, among other microorganisms, after two months of growth. 
Table 5. Lactuca sativa L. growing in Andisol inoculated with Penicillium albidum.

\begin{tabular}{|c|c|c|}
\hline & Control & P. albidum \\
\hline \multicolumn{3}{|l|}{ At seedling production stage } \\
\hline Shoot fresh weight (mg plant ${ }^{-1}$ ) & $53 \mathrm{~b}$ & $107 \mathrm{a}$ \\
\hline Root fresh weight (mg plant ${ }^{-1}$ ) & $10 \mathrm{~b}$ & $37 \mathrm{a}$ \\
\hline Olsen-P $\left(\mathrm{mg} \mathrm{kg}^{-1}\right)$ & $8.5 \mathrm{a}$ & $9.7 \mathrm{a}$ \\
\hline P-ase (mg p-NP g g soil h-1) & $202 \mathrm{~b}$ & $251 \mathrm{a}$ \\
\hline Number of colonies (CFU) & $2 \times 10^{4} \mathrm{~b}$ & $1 \times 10^{5} \mathrm{a}$ \\
\hline \multicolumn{3}{|l|}{ At harvest } \\
\hline Heart fresh weight (g plant $\left.{ }^{-1}\right)$ & $37 \mathrm{a}$ & $44 \mathrm{a}$ \\
\hline Stem fresh weight $\left(\mathrm{g} \mathrm{plant}^{-1}\right)$ & $8 \mathrm{a}$ & $9 \mathrm{a}$ \\
\hline Leaf fresh weight $\left(\mathrm{g} \mathrm{plant}^{-1}\right)$ & $23 \mathrm{a}$ & $29 \mathrm{a}$ \\
\hline Total fresh weight (g plant $\left.{ }^{-1}\right)$ & $68 \mathrm{~b}$ & $82 \mathrm{a}$ \\
\hline $\mathrm{P}$ in the foliage $\left(\mathrm{mg} \mathrm{kg}^{-1}\right)$ & $11.0 \mathrm{a}$ & $11.2 \mathrm{a}$ \\
\hline $\mathrm{K}\left(\mathrm{g} 100 \mathrm{~g}^{-1}\right)$ & $7 \mathrm{a}$ & $9 \mathrm{a}$ \\
\hline $\mathrm{Ca}\left(\mathrm{g} 100 \mathrm{~g}^{-1}\right)$ & $0.35 \mathrm{~b}$ & $0.50 \mathrm{a}$ \\
\hline $\operatorname{Mg}\left(g 100 g^{-1}\right)$ & $0.27 \mathrm{~b}$ & $0.35 \mathrm{a}$ \\
\hline $\mathrm{Mn}^{2+}\left(\mathrm{mg} \mathrm{kg}^{-1}\right)$ & $55 \mathrm{a}$ & $38 \mathrm{~b}$ \\
\hline $\mathrm{Cu}^{2+}\left(\mathrm{mg} \mathrm{kg}^{-1}\right)$ & $6.0 \mathrm{a}$ & $6.5 \mathrm{a}$ \\
\hline $\mathrm{Zn}^{2+}\left(\mathrm{mg} \mathrm{kg}^{-1}\right)$ & $27 \mathrm{a}$ & $29 \mathrm{a}$ \\
\hline $\mathrm{Fe}^{3+}\left(\mathrm{mg} \mathrm{kg}^{-1}\right)$ & $426 \mathrm{~b}$ & $561 \mathrm{a}$ \\
\hline
\end{tabular}

(Different letters show significant differences between the inoculated and control plants. $p<0.05$, Student's t-test).

The plants inoculated with P. albidum also showed a significant increase in the soil P-ase activity (Table 5), which was consistent with the high P-ase secretion by this fungus in liquid medium and the increased root development of the inoculated plants. It should be emphasised that fungal $\mathrm{P}$-ase is more effective in mineralising $\mathrm{P}$ than plant-derived $\mathrm{P}$-ase (Tarafdar et al., 2001). Therefore, the acid P-ase produced by $P$. albidum may be relevant to organic $\mathrm{P}$ mobilisation in volcanic soils that have a high content of organic $\mathrm{P}$ (Borie and Rubio, 2003).

It is noteworthy that, after transplantation, the lettuce continued to grow until reaching maturity (the commercial stage, heart stage) five months after planting. At the end of this stage, the inoculated plants presented, on average, greater development in the heart, leaves and stems than those that were not inoculated, with a significant increase in the gross weight of approximately $20 \%$ over the control (Table $5)$. These results also indicate, however, that the effects of this fungus are more relevant at the seedling stage of lettuce.

In addition, with the exception of $\mathrm{Mn}$, there was an increase in the concentration of macro- and micronutrients in the inoculated plants, particularly for $\mathrm{Ca}$, $\mathrm{Mg}$ and $\mathrm{Fe}$ (Table 5), which indicates that $P$. albidum 
favours the mineral nutrition of lettuce. Nevertheless, the slight increase in the P concentration in the inoculated plants, together with the notable increase in the fresh root weight at the seedling stage, suggests that mechanisms other than P solubilisation, such as the induction of root development, might have participated in the growth and mineral nutrition of the inoculated plants.

As reported in different studies (Whitelaw 2000; Yadav and Tarafdar, 2011), the favourable effect of Psolubilising fungi on the development of plants could be improved by co-inoculating the solubilising fungus with mycorrhizae (Kohler et al. 2007), which suggests that a joint inoculation of $P$. albidum with native mycorrhizae could have a synergic effect on the growth of lettuce. P. albidum was also able to promote the growth of clover in a volcanic soil under greenhouse conditions (Morales et al., 2007). Therefore, P. albidum appears to be a potential biofertiliser in volcanic soils, and its effect on other plants, in addition to its distinctive properties in $\mathrm{P}$ mobilisation, are currently being evaluated in our laboratory.

\section{Conclusions}

For most of the soils tested, the proportion of phosphofungi solubilising organic $\mathrm{P}$ and their solubilisation index were greater than those solubilising inorganic $\mathrm{P}$. The in vitro solubilisation of $\mathrm{P}$ was associated with the acidification of the medium.

Of those tested, the Asea-Wakelin medium appears to be best suited to evaluate the solubilising capacity of the phosphofungi isolated from the volcanic soils of southern Chile.

Due to its capacity to solubilise inorganic and organic $\mathrm{P}$, its specific solubilising activity, the secretion of phosphatase and the benefits to the growth and mineral nutrition of lettuce, the $P$. albidum phosphofungus appears to have the most potential as a solu- biliser and mineraliser of $\mathrm{P}$ in volcanic soils, and it is, therefore, appropriate to evaluate its effect on plants, either alone or co-inoculated with mycorrhizae.

\section{Acknowledgements}

We gratefully acknowledge the financial support of the DIUFRO DI08-0054 Grant (Universidad de La Frontera).

\section{References}

Agnihotri, V.P. 1970. Solubilization of insoluble phosphates by some soil fungi isolated from nursery seed beds. Can. J. Microbiol. 16, 877-880.

Asea, P.E.A., Kucey, R.M.N., Stewaert, J.W.B. 1988. Inorganic phosphate solubilization by two Penicillium species in solution culture and soil. Soil Biol. Biochem. 20, 459-464.

Barik, S.K., Pursuhothaman, C.S., Mohanty, A.N. 2001. Phosphatase activity with reference to bacteria and phosphorus in tropical freshwater aquaculture pond systems. Aquac. Res. 32(10), 819-832.

Borie, F., Rubio, R. 2003. Total and organic phosphorus in Chilean volcanic soils. Gayana Bot. 60, 69-78.

Borie. F., Quinteros, J., Aguilera, M. 1983. Bioquímica de suelos derivados de cenizas volcánicas IV. Solubilización de fosfatos por hongos del suelo. Agric. Téc. 43(4), 371-376.

Domsch, K., Gams, W., Traute-Heidi, A. 1995. Compendium of Soil Fungi. Ubrecht \&Cramer Ltd. Germany $405 \mathrm{p}$.

Fankem, H., Nwaga, D., Deubel, A., Dieng, L., Merbach, W., Etoa, F.X. 2006. Occurrence and functioning of phosphate solubilizing microorganisms from oil palm tree (Elaeis guineensis) rhizosphere in Cameroon. Afr. J. Biotechnol. 5(24), 24502460 . 
Irkin, R., Korukluoglu, M. 2009. Control of some filamentous fungi and yeasts by dehydrated Allium extracts. J. Verbrauch. Lebensm. 4(1), 3-6.

Kohler, J., Caravaca, F., Carrasco, L., Roldán, A. 2007. Interactions between a plant growthpromoting rhizobacterium, an AM fungus and a phosphate-solubilising fungus in the rhizosphere of Lactuca sativa. Appl. Soil Ecol. 35, 480-487.

Mäder, P., Fließbach, A., Dubois, D., Gunst, L., Fried, P., Niggli, U. 2002. Soil fertility and biodiversity in organic farming. Science 296, 1694-1697.

Martin, J. 1950. Use of acid, rose Bengal and streptomycin in the plate method for estimating soil fungi. Soil Sci. 69, 215-232.

Morales, A., Alvear, M., Valenzuela, E., Rubio, R., Borie, E. 2007. Effect of inoculation with Penicillium albidum, a phosphate-solubilizing fungus, on the growth of Trifolium pratense cropped in a volcanic soil. J Basic Microb 47, 275-280.

Murphy, Y., Riley, J.P. 1962. A modified single solution method for the determination of phosphate in natural waters. Anal. Chem. Acta 27, 31-36.

Nahas, E., Centurion, J.F., Assis, L.C. 1994. Microrganismos solubilizadores de fosfato e productores de fosfatases de vários solos. R. Bras. Ci. Solo $18,43-48$.

Pandey, A., Das, N., Kumar, B., Rinu, K., Trivedi, P. 2008. Phosphate solubilization by Penicillium spp. isolated from soil samples of Indian Himalayan region. World J. Microbiol. Biotechnol. 24, 97-102.

Pikovskaya, R.I. 1948. Mobilization of phosphorus in soil in connection with vital activity of some microbial species. Mikrobiologya 17, 362-370.

Ramírez, C. 1982. Manual and Atlas of the Penicillia. Amsterdam, Elsevier. Biomedical Press, 985 p.
Redel, Y., Rubio, R., Godoy, R., Borie, F. 2008. Phosphorus fractions and phosphatase activity in an Andisol under different forest ecosystems. Geoderma 145, 216-221.

Reyes, I., Bernier, L., Simard, R.R., Antoun, H. 1999. Effect of nitrogen source on the solubilization of different inorganic phosphate by an isolate of Penicillium rugulosum and two UV-induced mutants. FEMS. Microbiol. Ecol. 28, 281-290.

Rubio, R., Moraga, E., Borie, F. 1990. Acid phosphatase activity and vesicular-arbuscular mycorrhizal infection associated with roots of four wheat cultivars. J. Plant Nutr. 13(5), 585-598.

Sadzawka, A., Grez, R., Carrasco, M.A., and Mora, M.L. 2004. In: Métodos de análisis de tejidos vegetales. Comisión de Normalización y Acreditación. Sociedad Chilena de las Ciencia del Suelo, pp. 7-26.

Shannon, D., Sen, A.M., Johnson, D.B. 2002. A comparative study of the microbiology of soils managed under organic and conventional regimes. Soil Use Manage. 18, 274-283.

Tarafdar, J.C., Yadav, R.S., Meena, S.C. 2001. Comparative efficiency of acid phosphatase originated from plant and fungal sources. J. Plant Nutr. Soil Sc. 164(3), 279-282.

Vassileva, M., Serrano, M., Bravo, V., Jurado, E., Nikolaeva, I., Martos, V., Vassilev, N. 2010. Multifunctional properties of phosphate-solubilizing microorganisms grown on agro-industrial wastes in fermentation and soil conditions. Appl. Microbiol. Biotechnol. 85, 1287-1299.

Von Arx, J. 1981. The genera of fungi sporulating in pure culture. Verlag Von J. Cramer. Germany. 320 p.

Wakelin, S.A., Warren, R.A., Harvey, P.R., Ryder, M.H. 2004. Phosphate solubilization by Penicillium spp. closely associated with wheat roots. Biol. Fertil. Soils 40, 36-43. 
Wang, Y., Xu, J., Shen, J., Luo, Y., Scheu, S., Ke. X. 2010. Tillage, residue burning and crop rotation alter soil fungal community and water-stable aggregation in arable fields. Soil Till. Res. 107, 71-79.

Whitelaw, M. 2000. Growth promotion of plants inoculated with phosphate solubilizing fungi. Adv. Agron. 69, 99-151.
Xie, J., Knight, J.D., Leggett, M.E. 2009. Comparison of media used to evaluate Rhizobium leguminosarum bivar viciae for phosphate-solubilizing ability. Can. J. Microbiol. 55, 910-915.

Yadav, B.K., Tarafdar, J. C. 2011. Penicillium purpurogenum, unique $\mathrm{P}$ mobilizers in arid agroecosystems. Arid Land Res. Manag. 25(1), 87-99. 
